\title{
ANALIZA NAWIGACYJNA: UCZESTNICTWO W KULTURZE JAKO TWORZENIE ŻYCIA
}

\begin{abstract}
Rapior Waldemar, Analiza nawigacyjna: uczestnictwo w kulturze jako tworzenie życia [Navigational analytics: participation in culture as creation of life] edited by M. Krajewski - "Człowiek i Społeczeństwo", vol. XXXVI, iss. 2, Poznań 2013, pp. 277-288. Adam Mickiewicz University Press. ISBN 978-83-232-2672-7. ISSN 0239-3271.

Inspired by the research project entitled "Creating Culture. A Study of Participation in Culture" which I was co-creator, I aim at showing the methodology of building the bottom-up archive, and how can we use such an archive for the sociological purpose.

Waldemar Rapior, Uniwersytet im. Adama Mickiewicza w Poznaniu, Instytut Filozofii, ul. Szamarzewskiego 89c, 60-568 Poznań, Poland.
\end{abstract}

\begin{abstract}
"Każda utopia, opuszczając papier i stając między ludźmi, uniformizuje naga niezliczoność prób znalezienia życia, które byłoby możliwe do zniesienia. Każdy z nas składa się z tych prób i kontynuuje je aż do śmierci".
\end{abstract}

Herta Müller ${ }^{1}$

Głównym problemem języka teorii naukowej jest redukcja życia, licznych niuansów, zbyt drobnych i zbyt złożonych, aby można je było nazwać i uporządkować za pomocą neutralnego języka, zatem - jak zadbać o to, żeby życie zarejestrować i przedstawić ze wszystkimi jego detalami.

Charles Tilly podkreślał, że każde badanie empiryczne opiera się na dwóch korpusach teorii: teorii wyjaśniającej badane zjawisko oraz teorii wyjaśniającej dowody na występowanie tego zjawiska. Obie teorie nawzajem się implikują: „wszelkie twierdzenia dotyczące efektów stowarzyszania się implikują to, jak i gdzie możemy wykryć te efekty, ale równocześnie każde twierdzenie odnośnie do tego, jak można rozpoznać te efekty, ma

${ }^{1}$ H. Müller, Głód i jedwab, Wołowiec 2008, s. 57. 
wpływ na same ich właściwości” 2. Zasada „opisz całkowicie i dokładnie”, jak zauważył Robert Merton, nie pomaga badaczowi³. Należy skierować spojrzenie tam, gdzie tego chcemy. Wymaga to odpowiedzi na co najmniej cztery pytania: co obserwować, co włączyć do notatek z terenu, jak prezentować wyniki badań i co dalej z nimi zrobić. Projekt „Profile uczestników”, który jest częścią szerszego przedsięwzięcia badawczego „Tworzenie kultury - badanie uczestnictwa w kulturze" ${ }^{\prime \prime}$, polegał na stworzeniu katalogów zdarzeń. Tilly nazywa je „zespołem opisów licznych interakcji społecznych, wybranych z określonego zasobu źródeł według względnie ujednoliconej procedury” 6 . W przypadku projektu „Profile...” zasobem źródłowym był festiwal teatralny. Materiał otrzymany od informatorów wskazuje, że festiwal był dla nich narzędziem, z którego korzystali, budując swoją biografię. Rzeczywistym zasobem było samo życie. Analiza nawigacyjna, którą przedstawię, jest ujednoliconą metodą wyboru z życia opisów interakcji. Sytuuje ona jednostkę, jej zachowania, myśli i uczucia w pełnym szczegółów pejzażu relacji międzyludzkich, relacji z innymi istotami, przedmiotami i środowiskiem oraz przedstawia, jak jednostka korzysta $\mathrm{z}$ form, obiektów, obrazów i języków, aby opisywać i wytwarzać siebie, a tym samym świat, w którym żyje. Jest to zatem także pytanie o uczestnictwo w kulturze, o bycie integralnym elementem sytuacji uregulowanej kulturowo, przez co sytuacja ta przebiega zgoła odmiennie. Sformułowanie problemu $\mathrm{w}$ taki sposób wymaga zastosowania nowoczesnych narzędzi rejestrujących: kamer, aparatów fotograficznych, łączności komórkowej i usług lokalizacji bezprzewodowej. Opisy interakcji są $\mathrm{w}$ tym przypadku opisami audio-wideo.

Analiza nawigacyjna jest metodą kadrującą życie. Zajmę się tutaj teorią określającą sposób, w jaki dane zjawisko pozostawia ślady. Pominę teorię wyjaśniającą zjawisko, uczestnictwo w kulturze, choć - jak zobaczymy i jak podkreślał Tilly - obie teorie wpływają na siebie. Zatem mówiąc o produkcji katalogu zdarzeń, będę także mówił o uczestnictwie w kulturze. Pierwsza wskazówka teoretyczna pochodzi z literaturoznawstwa. Biografia i autobiografia są gatunkami literackim odtwarzającymi życie. Pytanie, na ile życie jest konstrukcją narracyjną, a na ile jest fikcją, nie musi nas w tej chwili zajmować. Ważny jest mechanizm biograficzny. Pozwala on odtworzyć

2 Ch. Tilly, Katalogi zdarzeń jako teorie, [w:] Nowe perspektywy teorii socjologicznej, red. A. Manterys, J. Mucha, Kraków 2009, s. 102.

3 R.K. Merton, Paradygmat analizy funkcjonalnej w socjologii, [w:] Wspótczesne teorie socjologiczne, t. 1, red. A. Jasińska-Kania, L.M. Nijakowski, J. Szacki, M. Ziółkowski, Warszawa 2006, s. 371.

${ }^{4}$ Por. www.tworzeniekultury.pl/profile-uczestnikow.html [dostęp: 29.01.2014].

${ }^{5}$ Por. www.tworzeniekultury.pl [dostęp: 29.01.2014].

${ }^{6}$ Ch. Tilly, op. cit., s. 102. 
trajektorię życia. Trajektoria to krzywa, którą zakreśla w przestrzeni poruszający się obiekt. Pisząc o trajektorii biografii, chcę podkreślić konkretną przestrzeń i konkretny czas, które są czasem i przestrzenią konkretnej osoby. Praktyką społeczną obrazującą trajektorię biograficzną jest nawigacja: korzystanie z tego, co pod ręką, aby orientować się w świecie, lecz nie tylko poprzez dekodowanie znaczeń, lecz również reagowanie na obiekty medialne i materialne. Odtwarzając nawigację, odtwarzamy biografię, czyli to, jak korzystamy z obiektów zastanych, uformowanych przez innych, ale też, poprzez użycie tych obiektów, kształtujemy je na nowo, w indywidualny lub zbiorowy i często nieprzewidywalny sposób.

\section{DZIENNIK WIZUALNY I MAPA ZDARZEŃ}

Projekt „Profile...” powstał dzięki współpracy Instytutu Socjologii UAM, Fundacji Malta, Fundacji UAM i grupy Kurator Art oraz wsparciu Narodowego Centrum Kultury w ramach programu Obserwatorium Kultury? W projekcie „Profile..." do procesu badawczego zostali włączeni uczestnicy Festiwalu Malta 2011. Byli to: Ewa, studentka kulturoznawstwa UAM; Bacha, studentka wiedzy o teatrze UAM; Jacopo, student z Włoch; Andrzej, trzydziestoletni poznaniak; Emilia, nauczycielka z Gdańska. Rozdaliśmy im minikamery Flip - małe i poręczne, z łatwością mieszczące się zarówno w dłoni, jak i w torebce lub kieszeni. Każdy z nich otrzymał dwa zadania do zrealizowania.

Pierwsze polegało na prowadzeniu wizualnego dziennika. Każdy uczestnik projektu miał rejestrować to, co robi podczas festiwalu. Należało filmować co trzy godziny (między 10.00 rano a 10.00 wieczorem) sytuację, w jakiej uczestnik właśnie się znajdował. Miał to być krótki fragment, trwający od jednej do trzech minut, zawierający panoramę sytuacji (obrót o $360^{\circ}$ z włączoną kamerą) oraz komentarz na temat miejsca pobytu, innych osób i wykonywanych działań. Drugim elementem dziennika wizualnego było filmowanie tych sytuacji, które wydawały się ciekawe i ważne dla samych informatorów i był najważniejszą częścią rejestracji. Gotowy materiał każdy uczestnik projektu miał posegregować w foldery (od poniedziałku, 4 lipca, do soboty, 9 lipca - w tych dniach trwał Festiwal Malta 2011) i ułożyć zgodnie z godziną powstania. Bacha opowiada koleżance, Alinie, o swoim zadaniu:

"- Do czego to będzie użyte?

- Wiesz co, nie wiem. To jest taki projekt socjologiczny, gdzie badają profile ludzi, którzy chodzą na Maltę. No, i generalnie mamy nagrywać co trzy godziny,

7 Por. www.obserwatoriumkultury.nck.pl [dostęp: 29.01.2014]. 
gdziekolwiek nie jesteśmy, mamy nagrać kilkuminutowy filmik; co robimy, gdzie idziemy, jakie mamy plany...

- Czyli chodzi o twój profil, a nie ludzi, o to, że ludzi wokół?

- Nie, nie, chyba mój. I tak są właśnie różne osoby. Jest też koleżanka mamy Judyty w to zaangażowana, więc ludzie w różnym wieku, różnie działający".

Drugim zadaniem było stworzenie „mapy zdarzeń, codziennej ścieżki działań $^{8}$. Każdej z osób rozdałem siedem kart formatu A4, po jednej na każdy dzień trwania festiwalu. Zawierały one informacje o dniu, którego dotyczą, oś czasu (od 8.00 rano do północy) oraz trzy linie wyznaczające miejsca przebywania informatorów: „dom", ,festiwal” i "pozostałe”, niefortunnie nazwane przeze mnie „przestrzenią publiczną". Następnie każda z osób zakreślała czas i miejsce, w jakich przebywała, wraz z opisem i nazwą pliku wideo z dziennika wizualnego. Za pomocą strzałek różnego typu (strzałka z linii ciągłych oznaczała poruszanie się pieszo, strzałka z linii przerywanych - rowerem, wypełniona - samochodem, a w pasy - transport publiczny) informatorzy oznaczali sposób poruszania się. Andrzej podczas spotkania z przyjaciółmi w ogródku piwnym, we wtorek, o godzinie 17.28 pokazuje mapę zdarzeń: „tu jest mój wykres festiwalowy. Na razie wypełniłem poniedziałek i to tylko do godziny mniej więcej 16.00, kiedy to spałem" wskazuje palcem na wykres i rysunek łóżka ze sobą pod kołdrą z komiksowym „zzzz" unoszącym się nad jego głową, po czym kontynuuje - „obudziłem się około godziny 13.00, Pogo [tak wabi się pies Andrzeja] bardzo chciał, żebym wyszedł na spacer i wyszedłem z nim na spacer. Ciąg dalszy nastąpi".

Na koniec przeprowadziłem, osobno $\mathrm{z}$ informatorami i osobno z osobą wskazaną przez informatora, z którą spędzał on/ona najwięcej czasu podczas festiwalu, wywiady pogłębione wspomagane materiałem wideo fragmentami z dzienników wizualnych.

Zdjęcia przedstawiają jeden dzień z życia Jacopo, sobotę podczas festiwalu. Fotografia 1 to kadry z dziennika wizualnego: Jacopo i Edu czekają na tramwaj około godziny 10.50, następnie słuchają wykładów podczas Forum dotyczącego związku estetyki i etyki. Potem wybierają się do parku i na spektakl Jana Fabre Prometheus Landscape II, a około godziny 23.00 na Starym Rynku uczestniczą w prezentacji Los Nadies grupy La Fura Dels Baus. Biorą też udział w silent disco, a po godzinie 5.00 rano zbierają się do domu. Fotografia 2 przedstawia mapę zdarzeń. Strzałki pokazują sposób przemieszczania się: strzałka w paski to transport publiczny, strzałka niewypełniona spacer. Fotografia 3 pokazuje stronę internetową, oddolne archiwum.

8 Por. A. Latham, Researching and Writing Everyday Accounts of the City: An Introduction to the Diary-photo Diary-interview Method, [w:] Picturing the Social Landscape Visual Methods and the Sociological Imagination, eds C. Knowles, P. Sweetman, London-New York 2004, i jego individual's daily path). 

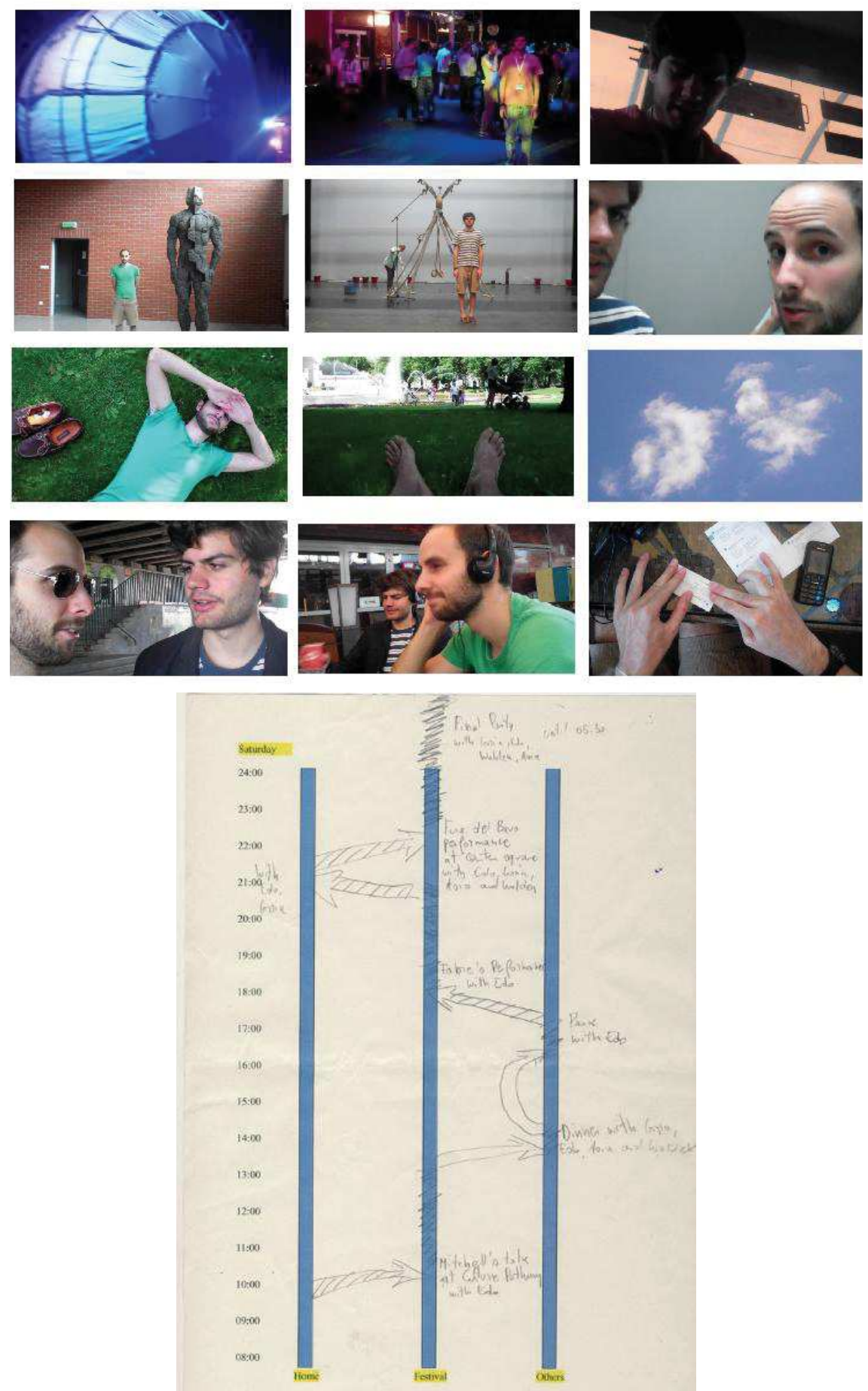


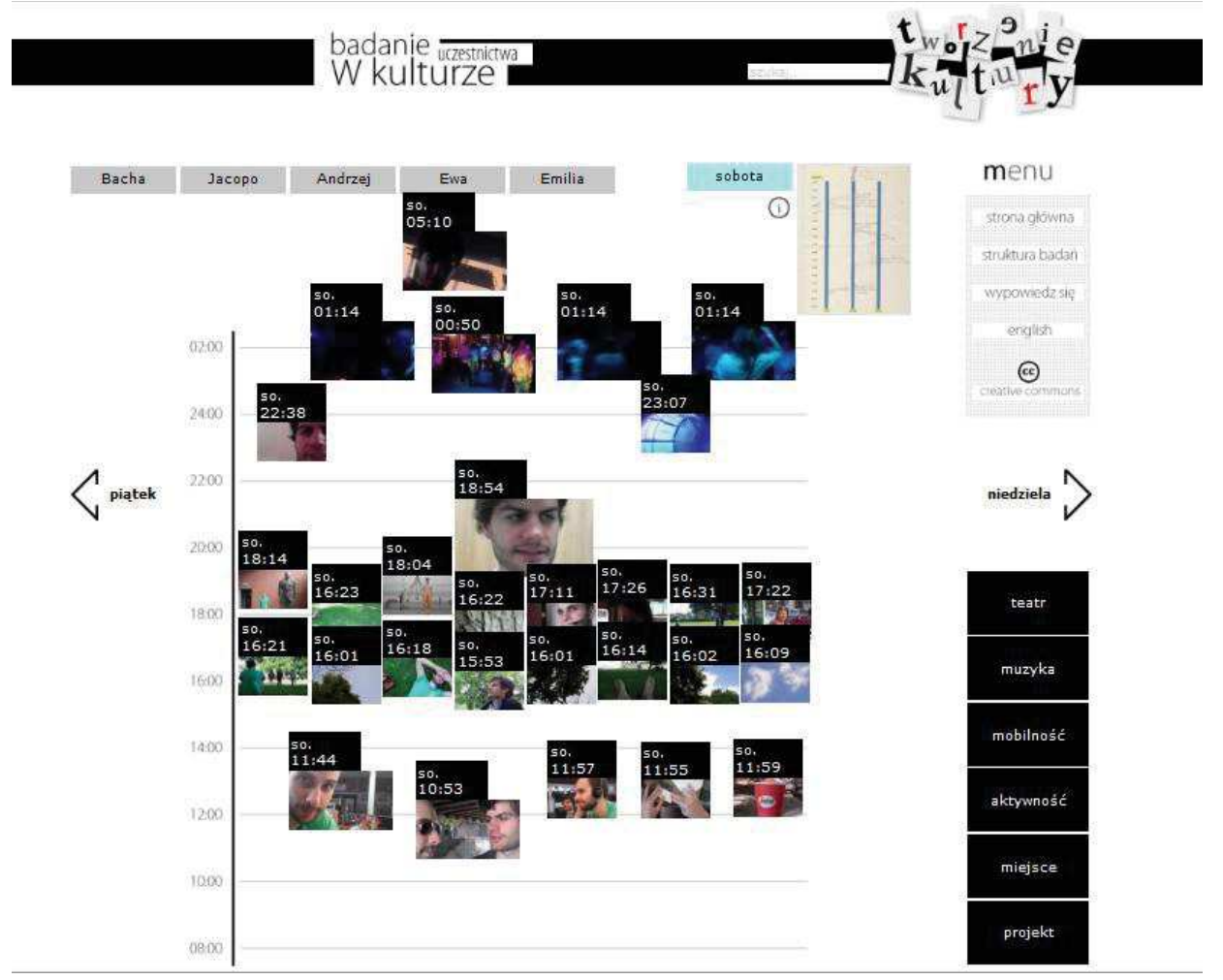

\section{ODDOLNE ARCHIWUM: REPOZYTORIUM FORM, OBIEKTÓW I RELACJI}

Kompletowanie katalogu zdarzeń jest narzędziem pomiaru. Decyzja, co znajdzie się $\mathrm{w}$ katalogu, pisał Tilly, implikuje teorię badanego zjawiska. $\mathrm{W}$ proces tworzenia katalogu, który nazywam rezerwuarem form, obiektów i relacji, włączeni zostali uczestnicy festiwalu. Taka procedura pozwala na podwójną analizę. Mechanizmy uczestnictwa w kulturze mogłem analizować na dwa sposoby, odrębnie lub łącząc je ze sobą: mogłem analizować "uczestnictwo w festiwalu" (włączanie festiwalu w życie uczestników) oraz "uczestnictwo w projekcie badawczym" (rozdanie kamer i zadań stworzyło sytuację uczestnictwa). Zastosowanie rezerwuaru form, obiektów i relacji to nie tylko pomiar i interpretacja - jest on formą archiwum.

W archiwum Fundacji Malta znajdują się materiały, od plakatów, taśm wideo z zapisem spektakli, do korespondencji z artystami i organizacjami czy dokumentów urzędowych, ze wszystkich dwudziestu jeden edycji Festiwalu Malta. Każdego roku wydarzenia festiwalowe są rejestrowane 
przez profesjonalną ekipę filmową. Pojawiają się pytania: kto kadruje życie, w jaki sposób jest rejestrowane, czy przez kamerę podłączoną do sprzętu nagłośnieniowego, $\mathrm{w}$ pomieszczeniu zaaranżowanym pod sytuację filmową, a nie "pod" osobę, z którą przeprowadzamy wywiad, czy też przez osoby zainteresowane, które same wybierają, co, gdzie i z kim filmują. Jeśli archiwum ma być oddolne, tworzone przez użytkowników, bardziej demokratyczne, proces kadrowania powinien leżeć w rękach uczestników. Zatem samoobserwacja, a nie obserwacja. Inaczej mówiąc, uczestnicy dzięki kamerze wideo (lub innemu instrumentowi rejestrującemu) mogą filmować każdy siebie samego oraz siebie nawzajem. Tak samo ważne jak to, co można zobaczyć lub usłyszeć w zarejestrowanym materiale, jest to, kiedy filmują uczestnicy. John Berger powtarzał, że w fotografii nie jest istotna kompozycja, ale wybór - wybór nie konkretnego obiektu, lecz tego, a nie innego momentu, $\mathrm{w}$ jakim go fotografujemy ${ }^{9}$. Podobnie jest $\mathrm{z}$ wideo. Wybór momentu, w którym informator filmuje sytuację, pozwala zbudować biograficzne sekwencje. Natomiast dzięki analizie obrazów - ruchomych bądź statycznych - możliwe jest odtworzenie, jak pewien element sytuacji - osoba (np. uczestnik), przedmiot (np. kamera wideo), zdarzenie (np. festiwal) wchodzi w relacje $z$ innymi osobami, przedmiotami, zdarzeniami.

Żadne archiwum nie jest kompletne, nie jest też neutralne. Zaletą oddolnego archiwum jest to, że tworzone jest przez uczestników. Badacz nie jest już jedyną instancją, która kształtuje i kontroluje sytuację badawczą - to badani stają się badaczami. Bacha, w rozmowie z koleżanką, tak to przedstawia: "to jest bardzo fajna sprawa, nie? Tak człowiek inaczej patrzy na miasto, się zastanawia, co by tu można nagrać". W wywiadzie przeprowadzonym po festiwalu powiedziała: „głównie zależało mi, wiadomo, też na ujęciu jakiegoś fajnego kadru, na rozmowach, bo rozmowy były w tym wszystkim najciekawsze" i dalej: „czasami tak się skupiałam, nie tyle na twarzy mojego rozmówcy, ile na rękach. Na przykład, kumpela mówi, że ma wąskie dłonie i może sobie taki pasek ściągnąć - Bacha lewą dłoń zaciska na prawym nadgarstku, imitując opaskę - bilet wstępu na koncert, a następnie demonstruje, jak jej znajoma ją ściągała przez wyprostowaną dłoń - jak się na koncert idzie, wiesz. I później opowiada, i to zupełnie inaczej człowieka pokazuje".

Strona internetowa tworzy kontekst dla krótkich filmów nagranych przez uczestników festiwalu. Nie przedstawia ona gotowej narracji. Użytkownik strony WWW może przeglądać kolejne filmiki pod kilkoma kątami: a) dziennik uczestnika festiwalu, dzień po dniu, godzina po godzinie, od

9 J. Berger, Zrozumieć fotografię, [w:] Badania wizualne w działaniu, red. M. Frąckowiak, K. Olechnicki, Warszawa 2011, s. 205. 
poniedziałku do niedzieli; użytkownik może śledzić, jak wyglądały dni poszczególnych osób, z kim się te osoby spotykały, jak spędzały czas, gdzie bywały i jak włączały festiwal w swoje życie; b) użytkownik może śledzić pojedynczy dzień z pięciu różnych perspektyw: Bachy, Jacopo, Andrzeja, Ewy i Emilii; często każdy z nich wybierał się na ten sam koncert lub spektakl, zatem te same sytuacje są pokazane $\mathrm{z}$ różnych punktów widzenia; c) użytkownik może śledzić poszczególne prezentacje maltańskie, sposób poruszania się uczestników i ich konkretne działania; w tym celu zostały przygotowane tagi ułożone w sześciu kategoriach: "teatr”, "muzyka”, "mobilność", "aktywność", "miejsce”, "projekt”. Ostatnia kategoria gromadzi filmy, na których uczestnicy wypowiadają się na temat projektu „Profile...". Również mapy zdarzeń zostały udostępnione użytkownikom. Strona internetowa jest rezerwuarem urywków z życia, ułożonych zgodnie z logiką biografii: poszczególnych osób, prezentacji maltańskich - jak spektakle albo koncerty stawały się częścią życia uczestników i jak ożywały w ich rozmowach, dyskusjach, wspomnieniach. Użytkownik, poruszając się po stronie internetowej, tworzy własną narrację o festiwalu.

\section{3. ŻYCIE: UWAGI METODYCZNE}

Zacznijmy od komentarza Eweliny. Rozmawiamy o materiale, który zarejestrowała podczas festiwalu: „najlepiej będzie, jeśli ja zostawię, tak jak jest, ale wtedy wychodzi nudne życie, tak? (śmiech). Nie robione na potrzeby filmu sytuacje, bo mogłabym gdzieś tam podchodzić do ludzi na ulicy i ich zagadywać, no, ale to już jest trochę inne zadanie, tak?". I dodaje: „ja mam takie poczucie zawodu, kiedy oglądam ten materiał, który został nakręcony, że to, to niczego nie pokazuje, tak?". Z czym związane jest to, co ważne: czy z niefotogenicznymi szczegółami, ulotnymi obrazami, dźwiękami, barwami, po części zauważonymi świadomie, po części nieświadomie, czy z wydestylowanymi i uporządkowanymi w elegancki sposób encyklopedycznymi chwilami, czy z ograniczonymi w swym zasięgu i zaaranżowanymi momentami wspólnotowego i intensywnie przeżywanego czasu? Życie, krzątanie się za swoimi sprawami, obywa się, choć z pewnością są jego częścią, bez spektakularnych zdarzeń, wartych sfotografowania i skatalogowania. Nie kryje za sobą jakiejś prawdy ogólnej lub przestrogi. Nie jest moralitetem. „Nudne”, gdyż zbyt wszechobecne i zbyt oczywiste, niedające się zapisać i zwerbalizować; "nie pokazuje”, gdyż odsyła tylko do siebie, a nie do jakiejś idei spajającej. Ale właśnie liczne i drobne szczegóły oddają niepowtarzalny charakter życia. 
Uczestnicy filmowali swoje życie, kadrując je, ale nie można z góry założyć, co jest ważne dla danego uczestnika. Trajektoria biograficzna nie uprzywilejowuje żadnej formy i momentu uczestnictwa: ani odbioru, ani produkcji, ani dekodowania treści symbolicznych, ani doświadczenia zmysłowego i cielesnego, ani tego, co zwykliśmy nazywać kulturą „wysoką”, ani kultury popularnej, ani najbardziej elementarnej ekspresji uczuciowej, ani najbardziej intelektualnej refleksji i krytyki. Skutek jest taki: odtwarzana praktyka nawigacyjna nie ukrywa tego, co istotne, gdyż każdy szczegół jest ważny dla życia. Nie wznosi barier między „wysokim” a „niskim”, między elitą a ludem, między ideami a życiem. Jeden z filmików przedstawia Bachę i jej przyjaciół pijących wino z butelek na Placu Wielkopolskim w Poznaniu, opustoszałym po godzinie 20.00 targowisku z metalowymi stoiskami pod plastikowym dachem namiotu. Są tuż przed koncertem Portishead. Rozmawiają o spektaklach widzianych poprzedniego dnia. Intelektualne rozmowy o sztuce - większość osób to studenci wiedzy o teatrze - łączą się $\mathrm{z}$ biesiadowaniem. Potem Bacha filmuje drogę, jaką przebywają na miejsce koncertu, wreszcie - sam koncert. Wszystko to, co przed koncertem, jest równie ważne jak sama muzyka. Festiwal nie jest tutaj rozumiany jako coś odrębnego od życia, jako karnawał, podczas którego wszelkie reguły ulegają odwróceniu, ale jako rezerwuar form, znaczeń, obrazów, przedmiotów; zbiór zasobów, które umożliwiają, w mniejszym lub większym stopniu, zawiązywanie, zrywanie i przekształcanie relacji z innymi ludźmi, wydarzeniami, obiektami. Festiwal, jak wszystko inne, jest narzędziem kształtowania życia, jest jednym z elementów życia, które się nie zatrzymuje i które trwa, zarówno przed, jak i po zakończeniu festiwalu, ale też festiwal jest jednym z elementów życia $\mathrm{w}$ takim sensie, że staje się budulcem dla naszego życia, tego, w jaki sposób doświadczamy świata, jak utwierdzamy się $\mathrm{w}$ jego rozumieniu lub odwrotnie, jak dochodzi do tego, że zaczynamy widzieć coś odmiennie.

Zasadniczym pytaniem jest: jak? Czy potrafimy odpowiedzieć na pytanie: dlaczego? - przykładowo, dlaczego ktoś dokonał jakieś innowacji? Czy potrafimy przedstawić wszystkie wpływy, jakie oddziałały na tę osobę? Czy ważniejsza była praca $\mathrm{w}$ laboratorium do późnych godzin nocnych, praca $\mathrm{w}$ tak zwanych kreatywnych przestrzeniach: $\mathrm{z}$ hamakiem, $\mathrm{z}$ zaparzaczem do kawy, z PlayStation, z gromadką znajomych on-line, czy może raczej kilkuminutowa rozmowa $\mathrm{z}$ nieznajomą kobietą lub mężczyzną na przystanku tramwajowym po całym dniu pracy? Nie jesteśmy $\mathrm{w}$ stanie wyodrębnić, nazwać, przedstawić i sklasyfikować wszystkich przyczyn. Możemy za to przedstawić życie tej osoby, zrozumieć, jak przebiegała trajektoria jej życia. Wyjaśnienia nie możemy szukać poza działającą jednostką. Pytanie ,jak?" stawia też w innym świetle problem kategoryzacji. Nie 
wystarczy rozpoznać cech wspólnych, takich jak płeć, wiek, wykształcenie, dochód. Dwie osoby o tych samych atrybutach mogą być zupełnie inne, gdyż struktura relacji, w jakich uczestniczą, jest równie istotna co wymienione wyżej zmienne ${ }^{10}$. I dalej, ważne są nie tylko sieci społeczne i rodzaj połączeń $\mathrm{w}$ ich obrębie, które można przedstawić za pomocą wykresu albo mapy relacji, lecz również to, jak zawiązywane, kształtowane, zmienianie, zrywane i utrwalane są więzi. Nie ma obiektywnych wzorów relacji społecznych, zawsze są one subiektywizowane przez działające ciało: umysł, ruch, mięśnie i stawy. Obserwacja nawigującego ciała pozwala zbudować trajektorię życia, biografię uczestnictwa w różnych zbiorowościach - państwie, rodzinie, szkole, fabryce, na giełdzie papierów wartościowych; $\mathrm{w}$ różnych miejscach - w biurze, $\mathrm{w}$ domu, na ulicy, w samolocie; $\mathrm{w}$ różnym czasie - za dnia i w nocy, rano bądź wieczorem, po pracy, w czasie pracy, przed pracą. Ludzie nie działają w zreifikowanym kontekście kulturowym. Jeśli chcemy mówić o reifikacji, to nie w kategoriach sytuacji zastanej, ale wyniku działań jednostek.

Wreszcie w przypadku analizy nawigacyjnej należy skupić się na środkach, a nie na celach. Nie możemy przewidzieć, jak cele zostaną osiągnięte, nie możemy przewidzieć zachowań ludzi. Możemy za to odnotowywać, ex post, postępy naszych działań. Aby osiągnięć cel, stosujemy różne środki, bardziej lub mniej standardowe. Przyjrzyjmy się kolejkom przed wejściem na biletowane prezentacje teatralne sfilmowanym przez uczestników projektu „Profile...”. Kolejki są integralną częścią festiwalu. Są też wyzwaniem dla organizatorów: jak zaprojektować przestrzeń lub jakie reguły zastosować, aby kolejki spełniały swoją funkcję. Funkcją kolejki jest porządkowanie przepływu ludzi zmierzających w określone miejsce. Pytamy wówczas: jak osiągnąć cel - jak efektywnie kontrolować przepływ ludzi oraz jak sprawnie dotrzeć do konkretnego punktu. Komputerowe modelowanie ruchu ludzi opiera się na algorytmach, określonej sekwencji poleceń, koniecznych, aby dotrzeć do celu. Filmy uczestników pokazują, że kolejki są zbyt złożoną formą. Każda osoba wnosi do nich swoje przyzwyczajenia, spotyka się z różnymi ludźmi, odgrywa różne role. Ponadto ludzie zaczynają rozpoznawać twarze osób zauważonych wcześniej w oczekiwaniu na inne wydarzenie. Kolejka nie jest zatem instrumentem skutecznego dotarcia do celu, ale środkiem więziotwórczym, częścią festiwalu, którą ludzie wykorzystują, aby się poznać, spędzić razem czas, wymienić opinie, pokazać się albo po prostu poczekać na początek spektaklu.

Analiza nawigacyjna jest narzędziem odtwarzającym życie jednostki, to, jak korzysta ona z tego, co pod ręką, aby tkać swoją indywidualną narrację,

10 Zob. H.C. White, Tożsamość i kontrola. Jak wyłaniają się formacje społeczne, Kraków 2011. 
ale nie tylko w sensie kognitywnym lub symbolicznym, ale poprzez operowanie przedmiotami, nawiązywanie znajomości, wzmacnianie lub zrywaniem więzi z innymi ludźmi.

\section{MYŚLEĆ INACZEJ}

Pojęcie tożsamości staje się coraz bardziej niebezpieczne. Z jednej strony jest nadużywane przez studia kulturowe i politykę tożsamości oraz wymóg od literatury poradnikowej po zakupy i reklamę - szukania i tworzenia swojej tożsamości, z drugiej strony akty terroryzmu, kryzysy finansowe i wojny klimatyczne powodują burzenie poczucia bezpieczeństwa i zwracanie się ku stabilnym tożsamościom, zdecydowanym lojalnościom; ku niespokojnemu wycofaniu się w plemiona i wspólnoty. Tożsamości, struktury i lojalności nie determinują życia jednostek i społeczności. Są one raczej skutkiem ludzkich działań. Ideologie są zawsze słabsze od aspiracji i interesów ich nosicieli. Nie jesteśmy reprezentantami jakichś wyższych kategorii, jakichś ogólniejszych prawd, wytworem jakichś standardów, np. przeciwstawienia cielesnego pożądania - miłości do czystych idei ${ }^{11}$. Życie nie jest alegorią różnicy kulturalnej, seksualnej, rasowej, narodowej albo klasowej. Nie tworzy relacji między człowiekiem a jakąś normą (np. heteroseksualną rodziną, lojalnym patriotyzmem, światowym kosmopolityzmem). Różnica narodowa jest raczej wytworem pedagogicznego kapitału zainwestowanego przez państwo w obywateli, różnica klasowa jest raczej produktem forsowania konkretnych interesów, spekulacji finansowej i mentalności skierowanej na zysk. Standardy, różnice i normy są tworzone i kształtowane przez poszczególne jednostki, tworzące i działające w obrębie mniej czy bardziej uporządkowanych instytucji, a więc zespołu reguł i znaczeń stabilizujących interakcje społeczne. Każda kobieta i każdy mężczyzna są poszczególnymi ludźmi, którzy nawigują, czyli próbują znaleźć życie możliwe do zniesienia. Trajektoria biograficzna jest narzędziem badawczym odtwarzającym te próby.

\section{BIBLIOGRAFIA}

Berger J., Zrozumieć fotografię, [w:] Badania wizualne w działaniu, red. M. Frąckowiak, K. Olechnicki, Warszawa 2011.

Latham A., Researching and Writing Everyday Accounts of the City: An Introduction to the Diary-photo Diary-interview Method, [w:] Picturing the Social Landscape Visual Methods

${ }^{11}$ A. Touraine, Myśleć inaczej, Warszawa 2011, s. 239-243. 
and the Sociological Imagination, eds C. Knowles, P. Sweetman, London-New York 2004.

Merton R.K., Paradygmat analizy funkcjonalnej w socjologii, [w:] Wspótczesne teorie socjologiczne, t. 1, red. A. Jasińska-Kania, L.M. Nijakowski, J. Szacki, M. Ziółkowski, Warszawa 2006.

Tilly Ch., Katalogi zdarzeń jako teorie, [w:] Nowe perspektywy teorii socjologicznej, red. A. Manterys, J. Mucha, Kraków 2009.

Touraine A., Myśleć inaczej, Warszawa 2011.

White H.C., Tożsamość i kontrola. Jak wyłaniają się formacje społeczne, Kraków 2011. 